\title{
Clavulanic Acid
}

National Cancer Institute

\section{Source}

National Cancer Institute. Clavulanic Acid. NCI Thesaurus. Code C61681.

A semisynthetic beta-lactamase inhibitor isolated from Streptomyces. Clavulanic acid contains a beta-lactam ring and binds strongly to beta-lactamase at or near its active site, thereby hindering enzymatic activity. This protects other beta-lactam antibiotics from beta-lactamase catalysis, thereby enhancing their antibacterial effects. This agent is used in conjunction with beta-lactamase susceptible antibiotics, such as penicillins and cephalosporins, to treat infections caused by beta-lactamase producing organisms. 